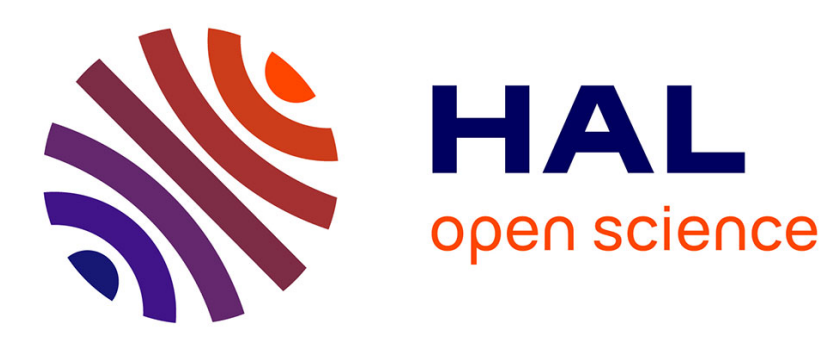

\title{
Real-time electrochemical LAMP: a rational comparative study of different DNA intercalating and non-intercalating redox probes
}

Alexandra Martin, Laurent B Bouffier, Kathryn B Grant, Benoît B Limoges, Damien Marchal

\section{To cite this version:}

Alexandra Martin, Laurent B Bouffier, Kathryn B Grant, Benoît B Limoges, Damien Marchal. Realtime electrochemical LAMP: a rational comparative study of different DNA intercalating and nonintercalating redox probes. Analyst, 2016, 141 (13), pp.4196 - 4203. 10.1039/C6AN00867D . hal01376606

\section{HAL Id: hal-01376606 \\ https://hal.science/hal-01376606}

Submitted on 5 Oct 2016

HAL is a multi-disciplinary open access archive for the deposit and dissemination of scientific research documents, whether they are published or not. The documents may come from teaching and research institutions in France or abroad, or from public or private research centers.
L'archive ouverte pluridisciplinaire HAL, est destinée au dépôt et à la diffusion de documents scientifiques de niveau recherche, publiés ou non, émanant des établissements d'enseignement et de recherche français ou étrangers, des laboratoires publics ou privés. 


\title{
Analyst
}

\section{PAPER}

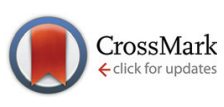

Cite this: Analyst, 2016, 141, 4196

\section{Real-time electrochemical LAMP: a rational comparative study of different DNA intercalating and non-intercalating redox probes $\uparrow$}

\author{
Alexandra Martin, ${ }^{a}$ Laurent Bouffier, ${ }^{b}$ Kathryn B. Grant, ${ }^{c}$ Benoît Limoges*a and \\ Damien Marchal*a
}

\begin{abstract}
We present a comparative study of ten redox-active probes for use in real-time electrochemical loopmediated isothermal amplification (LAMP). Our main objectives were to establish the criteria that need to be fulfilled for minimizing some of the current limitations of the technique and to provide future guidelines in the search for ideal redox reporters. To ensure a reliable comparative study, each redox probe was tested under similar conditions using the same LAMP reaction and the same entirely automatized custom-made real-time electrochemical device (designed for electrochemically monitoring in real-time and in parallel up to 48 LAMP samples). Electrochemical melt curve analyses were recorded immediately at the end of each LAMP reaction. Our results show that there are a number of intercalating and nonintercalating redox compounds suitable for real-time electrochemical LAMP and that the best candidates are those able to intercalate strongly into ds-DNA but not too much to avoid inhibition of the LAMP reaction. The strongest intercalating redox probes were finally shown to provide higher LAMP sensitivity, speed, greater signal amplitude, and cleaner-cut DNA melting curves than the non-intercalating molecules.
\end{abstract}

Received 14th April 2016, Accepted 8th May 2016

DOI: $10.1039 / c 6 a n 00867 d$ www.rsc.org/analyst dynamic range, including a faster analytical response. Towards this end, a major effort has gone into the integration of the gold standard method of nucleic acid analysis, i.e., the fluorescence-based real-time PCR, in portable lab-on-chip miniaturized devices. ${ }^{3-5}$ However, to date, real-time PCR has only seen slow transition to POC, in part because of the need for precise thermal cycling, but also because of the requirement for a rather complex, fragile and costly miniaturized fluorescence-based optical detection system. In order to circumvent these limitations, isothermal methods for nucleic acid amplification combined with electrochemical detection, were recently proposed. ${ }^{6-9}$ These approaches reduce or eliminate the need for accurate temperature control and cycling, thus affording the development of simpler and smaller battery-operated portable devices. ${ }^{10,11}$ Also important are the numerous advantages offered by electrochemical detection, namely lowercost, facile integration in a miniaturized format, good sensitivity, high robustness without need for periodic recalibration, and the ability to operate in non-transparent reaction mixtures and reaction vessels with complex biological samples. ${ }^{6-8,12}$

To date, only two isothermal DNA amplification methods have been coupled to real-time electrochemical monitoring, i.e. helicase-dependent amplification $(\mathrm{HDA})^{13}$ and loopmediated isothermal amplification (LAMP). ${ }^{14-19}$ These couplings are almost all based on the time-course electrochemical 
(or electrical) measurement of a binding reaction occurring between an indicator added to the reaction solution and the DNA products or pyrophosphate ions generated by the isothermal amplification reaction. One exception is the real-time monitoring of LAMP reaction through a $\mathrm{pH}$ change, but the resulting LAMP performance suffers from a lack of sensitivity because of the need to record very small $\mathrm{pH}$ variations. ${ }^{18}$ For the other approaches, two detection strategies were proposed. The first one takes advantage of a change in the electrical conductivity of the reaction solution to monitor the progress of an LAMP reaction, ${ }^{16,17}$ while the second one is an adaptation of a detection strategy previously demonstrated for real-time electrochemical PCR. ${ }^{20,21}$ The latter relies on the in situ measurement of the faradaic current response decrease of a free-to-diffuse intercalating redox probe as the reaction progresses. This detection strategy was demonstrated first with the isothermal HDA method ${ }^{13}$ and thereafter with LAMP. ${ }^{14,15}$ So far, only three redox-active probes have been reported. The first one is $\left[\mathrm{Os}(\mathrm{bpy})_{2} \mathrm{dppz}\right]^{2+}\left(\mathrm{dppz}=\operatorname{dipyrido}\left[3,2-a: 2^{\prime}, 3^{\prime}-c\right]\right.$ phenazine), a reversible one-electron oxidizing metal complex that exhibits strong preferential binding to ds-DNA (binding constant $K_{\mathrm{b}}>10^{6} \mathrm{M}^{-1}$ at $25{ }^{\circ} \mathrm{C}$ ), good chemical and thermal stability, and high electrochemical detection sensitivity. It has however some shortcomings: (i) it inhibits the polymerase activity (both under PCR and HDA conditions) at high concentration $(>\mu \mathrm{M})$ and (ii) it gives significant background drift that can complicate signal analysis and interpretation. ${ }^{13,20}$ The second probe is methylene blue ( $\mathrm{MB}$ ), a two-electron redoxactive molecule that intercalates into ds-DNA with a $\sim 100$-fold lower binding affinity than the $\left[\mathrm{Os}(\mathrm{bpy})_{2} \mathrm{dppz}\right]^{2+}$ complex. This lower affinity was found to be detrimental in real-time electrochemical PCR since no significant electrochemical signal decrease could be observed, ${ }^{20}$ but not in real-time electrochemical LAMP where an exponential decrease of the current response with time was reported. ${ }^{15,19}$ The last probe is the reversible one-electron metal complex $\mathrm{Ru}\left(\mathrm{NH}_{3}\right)_{6}{ }^{3+} \cdot{ }^{22}$ Though this compound lacks ds-DNA intercalating properties, it was shown to give a current response decrease during LAMP that was ascribed to an electrostatic interaction of $\mathrm{Ru}\left(\mathrm{NH}_{3}\right)_{6}{ }^{3+}$ with the anionic DNA backbone of amplicons. ${ }^{22}$ However, the poor temporal resolution as well as the high data scattering in the published work hamper judgement of the LAMP performances with this particular redox probe.

Though the analytical performances of real-time electrochemical LAMPs so far developed look attractive and potentially competitive with optical fluorescence-based methods, ${ }^{14-19,22}$ it is not possible to accurately compare them, each being carried out under different conditions using different DNA targets and redox probes. It is therefore not obvious to identify which redox probes are more favorable for LAMP. Moreover, there exists a wide range of unexplored redox compounds that could potentially solve some of the current limitations of the technique (i.e., poor stability of background response, inhibition of polymerase, lack of reproducibility and sensitivity), but it is unclear what criteria must be fulfilled to the design of an appropriate redox reporter. For all of these reasons, we present here a comparative study of ten different redox-active probes for use in real-time electrochemical LAMP, with the main objective to provide guidelines in the search for ideal redox reporters but also to establish the criteria that are required for improving and optimizing the method. These guidelines are anticipated to be useful to others who are interested in designing new redox probes, in applying real-time electrochemical LAMP to downstream applications, and in extending the detection strategy to others isothermal DNA amplification techniques.

To ensure a reliable comparative study, each redox reporter was tested in the same LAMP reaction, i.e. in a target model system involving the LAMP amplification of a 274 bp DNA sequence from bacteriophage M13mp18, ${ }^{23}$ and using the same entirely automatized custom-made real-time electrochemical device. ${ }^{13,24}$ The electrochemical LAMPs performed for each of the redox-active probes were followed at the end of the reaction with a melt curve analysis, a useful strategy for identifying and differentiating well-amplified full-length amplicons from nonspecifically generated DNA products.

\section{Experimental}

\section{Reagents}

All oligonucleotides were purchased from Eurogentec. The BIP, FIP, B3 and F3 sequences used to specifically amplify a 274 bp DNA target in M13mp18 were previously reported in the literature. $^{23}$ LB (5'-CGA GCT CGA ATT CGT AAT CA-3') and LF (5'-CTT GCA GCA CAT CCC CCT TT-3') sequences were designed specifically for this study. The M13mp18 DNA was obtained from New England Biolabs Inc.

The Bst 2 WarmStart ${ }^{\mathrm{TM}}$ DNA polymerase and buffer were provided by New England Biolabs Inc. Bovine serum albumin (BSA), polyvinylpyrrolidone (PVP, MW $40 \mathrm{kDa}$ ) and betaine solution were supplied by Sigma Aldrich. For electrochemical measurements, a $10 \times$ homemade detergent-free Tris buffer (10× TB, pH 8.8: 0.2 M Tris- $\mathrm{HCl}, 500 \mathrm{mM} \mathrm{KCl,} 0.1 \mathrm{M}\left(\mathrm{NH}_{4}\right)_{2} \mathrm{SO}_{4}$ and $0.04 \mathrm{M} \mathrm{MgSO}_{4}$ ) was used. The osmium complexes $\mathrm{Os}(\mathrm{bpy})_{3}\left(\mathrm{PF}_{6}\right)_{2},\left[\mathrm{Os}(\mathrm{bpy})_{2} \mathrm{phen}\right]\left(\mathrm{PF}_{6}\right)_{2}$, and $\left[\mathrm{Os}(\mathrm{bpy})_{2} \mathrm{dppz}\right]\left(\mathrm{PF}_{6}\right)_{2}$ (where bpy $=2,2^{\prime}$-bipyridine, phen $=$ phenanthroline, and dppz $=$ dipyrido[3,2-a:2',3'-c]phenazine) were synthetized according to published procedures. ${ }^{25}$ Methylene blue (MB), Nile blue, and ferrocene boronic acid $\left(\mathrm{FcB}(\mathrm{OH})_{2}\right)$ were supplied by Sigma-Aldrich. The hexafluorophosphate salt of (ferrocenylmethyl)trimethylammonium $\left(\mathrm{FcCH}_{2} \mathrm{NMe}_{3} \mathrm{PF}_{6}\right)$ was obtained by metathesis of the corresponding iodide salt (Alfa Aesar). The methylene blue derivative ( $\mathrm{PhP}$ ) and the pyridoacridone derivative (PyA) were synthesized according to published procedures. $^{26-28}$

\section{Real-time electrochemical LAMP}

The real-time electrochemical monitoring of LAMP was carried out with a custom-designed instrument consisting of a flat Peltier-heating block over which a single-use 48-well electrochemical microplate was fastened flat and electrically con- 
nected to a multiplexed potentiostat through two underlying arrays of 72-pin connector integrated to the heating block (Easy Life Science). ${ }^{13}$ The flat bottom of each well of the microplate was printed with 3 screen-printed electrodes: a carbon working electrode, a carbon counter electrode and a silver pseudo-reference electrode. With this device the content of each of the 48-electrochemical wells (i.e., working volumes of solution ranging from 25 to $75 \mu \mathrm{L}$ ) could be held at a constant temperature (typically $65{ }^{\circ} \mathrm{C}$ for LAMP) and scanned by square wave voltammetry (SWV) at a maximal sampling rate of $0.3 \mathrm{~Hz}$. (The 48 electrochemical wells could be scanned once by SWV over $0.6 \mathrm{~V}$ in less than $5 \mathrm{~s}$.) With the help of a dedicated Matlab program, SWV peak current integrations were automatically extracted from raw signals after baseline correction, before being plotted as a function of the LAMP amplification time.

Wells of the electrochemical microplate were each filled with $50 \mu \mathrm{L}$ of LAMP reaction mixture containing $400 \mu \mathrm{M}$ of each of the dNTPs (Qiagen), $5 \mu \mathrm{L} 10 \times \mathrm{TB}, 1.6 \mu \mathrm{M}$ of each of the BIP and FIP primers, $0.8 \mu \mathrm{M}$ of each of the LB and LF primers, $0.4 \mu \mathrm{M}$ of each of the $\mathrm{B} 3$ and $\mathrm{F} 3$ primers, $1 \mathrm{mM}$ betaine, 0.025 wt $\%$ BSA, 1 wt\% PVP, 0.32 U of Bst 2 WarmStart ${ }^{\mathrm{TM}}$ DNA polymerase, a suitable amount of the redox reporter (see text), and $2 \mu \mathrm{L}$ target DNA, and then sealed with an adhesive film (MicroAmp® optical adhesive film, Thermo Fisher Scientific) to avoid evaporation during the amplification process. LAMP reaction mixes were maintained at $65{ }^{\circ} \mathrm{C}$ during the amplification reaction while the SWV responses of each well were recorded at a suitable sampling rate (i.e., every $40 \mathrm{~s}$ ). Melt curve analysis was performed immediately following the LAMP reaction by applying a linear ramp of temperature starting from $50{ }^{\circ} \mathrm{C}$ to $91^{\circ} \mathrm{C}$ at a ramp rate of a $1.1^{\circ} \mathrm{C} \mathrm{min}^{-1}$ with concurrent monitoring of the SWV signals every $13 \mathrm{~s}$.

\section{Results and discussion}

The principle of the LAMP method under consideration is recalled in Scheme 1. It relies on the in situ and real-time

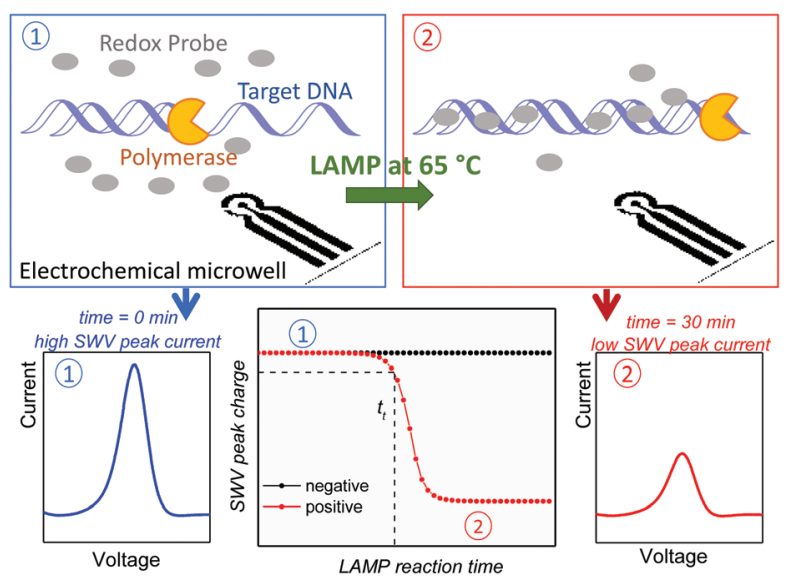

Scheme 1 Schematic diagram of the real-time electrochemical LAMP. electrochemical monitoring of faradaic current response (using SWV) generated from a free-to-diffuse intercalating redox probe added to the LAMP reaction mixture. As the reaction progresses, an exponential amount of the redox reporter intercalates into the exponentially amplified double-stranded amplicons. The consequence of this binding is a lowering of the apparent mass transport of the redox indicator to the electrode surface (because of the lower diffusion coefficient of the bound $v s$. free redox active probe). This then translates into an exponential decrease of the faradaic current response as a function of the amplification time for positive samples, while there is no change for negative controls (no target).

\section{Description of the redox-active probes}

As it was previously reported by us, ${ }^{13,20}$ an ideal redox probe should meet the following criteria, having: (i) strong and preferential binding affinity for ds-DNA, (ii) good chemical and thermal stability, (iii) a weak inhibitory effect on the amplification reaction, (iv) a stable current response in the absence of target DNA, and (v) good electrochemical detection sensitivity within an accessible potential window in water. In the present work, we have selected ten redox-actives molecules which satisfy more or less these criteria (Scheme 2). Their formal potentials $\left(E^{0^{\prime}}\right)$ span over a large potential window (i.e., from $-0.51 \mathrm{~V}$ to $+0.65 \mathrm{~V}$, Scheme 2). Three are one-electron reversible osmium-based bipyridyl complexes, which were chosen not only because of their large differences in ds-DNA binding affinity, but also because of their well-defined electrochemical properties.

Strong ds-DNA intercalation by the first $\left[\mathrm{Os}(\mathrm{bpy})_{2} \mathrm{dppz}\right]^{2+}$ complex $\left(K_{\mathrm{b}}>10^{6} \mathrm{M}^{-1}\right.$ at $25^{\circ} \mathrm{C}$, ref. 20 and 29$)$ mainly results from the dipyridophenazine ligand, which stacks in between the base pairs of ds-DNA. ${ }^{29,30}$ The second osmium complex $\left[\mathrm{Os}(\mathrm{bpy})_{2} \text { phen }\right]^{2+}$ has a much lower ds-DNA affinity $\left(K_{\mathrm{b}} \sim 8 \times\right.$ $10^{3} \mathrm{M}^{-1}$, ref. 31 ), while the last one, the Os(bpy $)_{3}{ }^{2+}$, completely

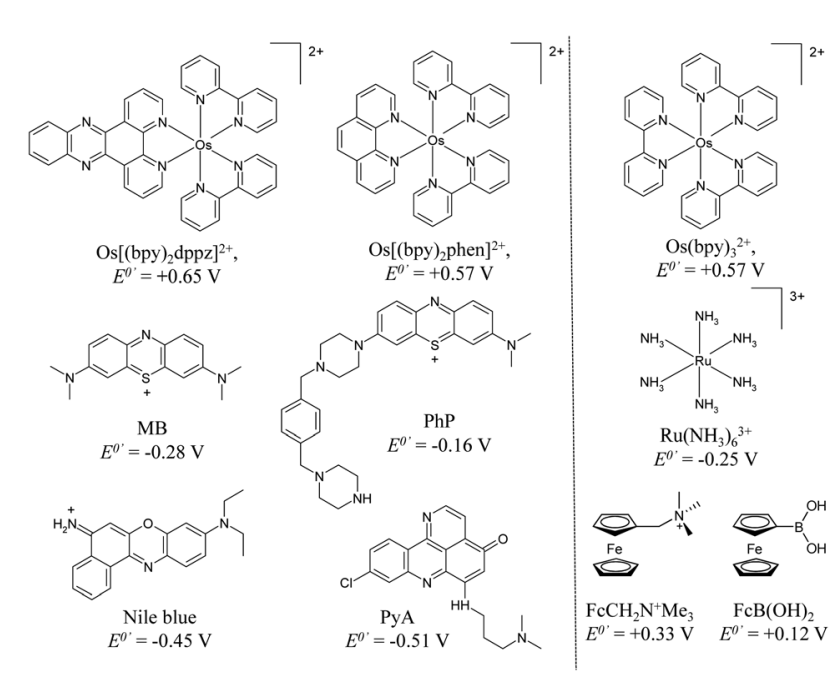

Scheme 2 List of redox probes selected for real-time electrochemical monitoring of LAMP. Formal potentials $\left(E^{\mathrm{O}^{\prime}}\right)$ are at $\mathrm{pH} 8.8$ and vs. $\mathrm{Ag} /$ $\mathrm{AgCl}$. 
lacks ds-DNA intercalating properties. Among the remaining redox intercalating compounds in Scheme 2, two belong to a class of electroactive heterocyclic polyaromatic dyes able to reversibly exchange $2 \mathrm{e}^{-}+2 \mathrm{H}^{+}$through their quinoid functional group. Included in this category are methylene blue $\left(\mathrm{MB} ; K_{\mathrm{b}}\right.$ of $10^{4}-10^{5} \mathrm{M}^{-1}$ at $20-25^{\circ} \mathrm{C}$, ref. $\left.32-34\right)$ and a MB derivative baptized PhP. The latter is modified with a DNA anchor arm (i.e., a piperazinexylene chain) so as to substantially increase (by a factor $\sim 10$ ) the binding affinity of the phenothiazine ring to ds-DNA. ${ }^{35}$ The MB probe was previously used for the real-time electrochemical monitoring of LAMP reactions. ${ }^{14,15,19}$ It can thus serve as a valuable reference for comparison of the present study to previously reported works. Additional heterocyclic polyaromatic electroactive dyes in Scheme 2 are Nile blue and a pyridoacridone derivative (PyA). Both have an extended flat polyaromatic structure favorable to ds-DNA intercalation $\left(K_{\mathrm{b}} \sim 10^{4}-10^{6} \mathrm{M}^{-1}\right.$, ref. 36 and 37). The list of reporters is completed by several non-intercalating redox compounds, i.e., the ruthenium hexaamine $\left(\mathrm{Ru}\left(\mathrm{NH}_{3}\right)_{6}{ }^{3+}\right)$, also previously used, ${ }^{22}$ and two ferrocene derivatives, the positively charged

(ferrocenylmethyl)trimethylammonium $\left(\mathrm{FcCH}_{2} \mathrm{~N}^{+} \mathrm{Me}_{3}\right)$ and neutral ferrocenyl boronic acid $\left(\mathrm{FcB}(\mathrm{OH})_{2}\right)$. Overall, the ten redox reporters selected in this study can be classified in two categories: those that are recognized for their ds-DNA intercalating properties and others that are not (separated by the dashed vertical line in Scheme 2).

\section{Characterization of the probes}

In order to have a rigorous side-by-side comparison of the 10redox probes, each was examined for its ability to monitor electrochemically and in real-time the LAMP amplification of a M13mp18 ds-DNA target under identical experimental conditions. Fig. 1 and 2 show the experimental data obtained for each of the redox-active probes during the real-time electrochemical LAMP of M13mp18 (in Fig. 1 are the results for the intercalating probes whereas in Fig. 2 are those for the nonintercalating ones). A starting DNA target concentration of $10^{6}$ copies per well was selected for all of the positive samples, while the negative template controls were run without DNA. Depending on whether or not there was a propensity to inhibit the LAMP reaction, but also to provide at $65{ }^{\circ} \mathrm{C}$ a sensitive SWV response with a large amplitude decrease, the concentration of each of the redox-active probes was suitably adjusted. The first column of the graphs in Fig. 1 and 2 reports the SWV responses recorded during LAMP at three different amplification times. Well-defined SWV peaks centered on the $E^{0^{\prime}}$ of each redox reporter were obtained for all of the selected compounds except for PyA.t Depending on the redox probe, the SWV peaks of positive samples compared to the negative controls were observed to suddenly decrease and even sometimes disappear as a function of the LAMP amplification time.

$\$$ The atypical shape of the SWV response of PyA was found to result from the redox-mediated catalytic reduction of dissolved dioxygen by the electrochemically reduced form of PyA, a reaction that is expected to occur efficiently at the low reduction potential of PyA $\left(E^{0 t}=-0.51 \mathrm{~V} v s\right.$. $\left.\mathrm{Ag} / \mathrm{AgCl}\right)$.
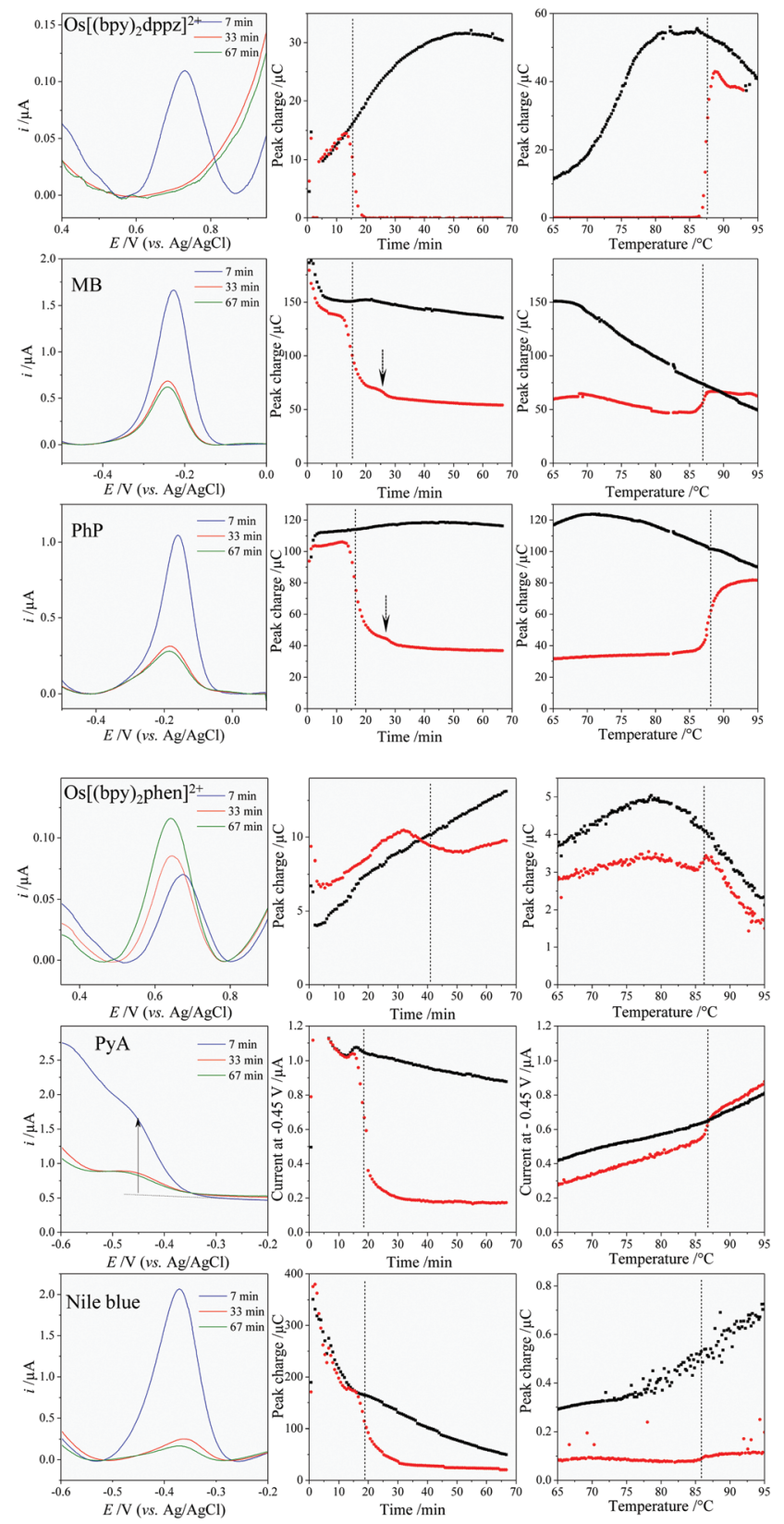

Fig. 1 Intercalating redox probe data. Left column: SWV responses recorded at different time interval during LAMP of a positive sample $\left(10^{6}\right.$ copies of M13mp18 DNA target) (blue) after 7, (red) 33 and (green) 67 min reaction times. (On the PyA graph, the arrow indicates how the SWV current at $-0.45 \mathrm{~V}$ was measured with this particular probe). Middle column: real-time SWV peak charge (or SWV peak current for PyA) traces for negative (no DNA target, black) and positive samples $\left(10^{6}\right.$ copies of M13mp18 DNA target, red). Right column: melt curves recorded after LAMP for positive (red) and negative controls (black). The redox reporter is indicated on the left corner of each SWV graph (from top to bottom): $0.5 \mu \mathrm{M}\left[\mathrm{Os}(\mathrm{bpy})_{2} \mathrm{dppz}\right]^{2+}, 15 \mu \mathrm{M} \mathrm{MB}, 15 \mu \mathrm{M} \mathrm{PhP}, 0.5 \mu \mathrm{M}$ $\left[\mathrm{Os}(\mathrm{bpy})_{2} \text { phen }\right]^{2+}, 5 \mu \mathrm{M}$ PyA and $5 \mu \mathrm{M}$ Nile Blue.

Reporting the SWV peak charges (except for PyA where the magnitude of the SWV cathodic current at $-0.45 \mathrm{~V}$ was instead reported as a function of time) as a function of LAMP reaction time (graphs in the middle column of Fig. 1 and 2) allow one 

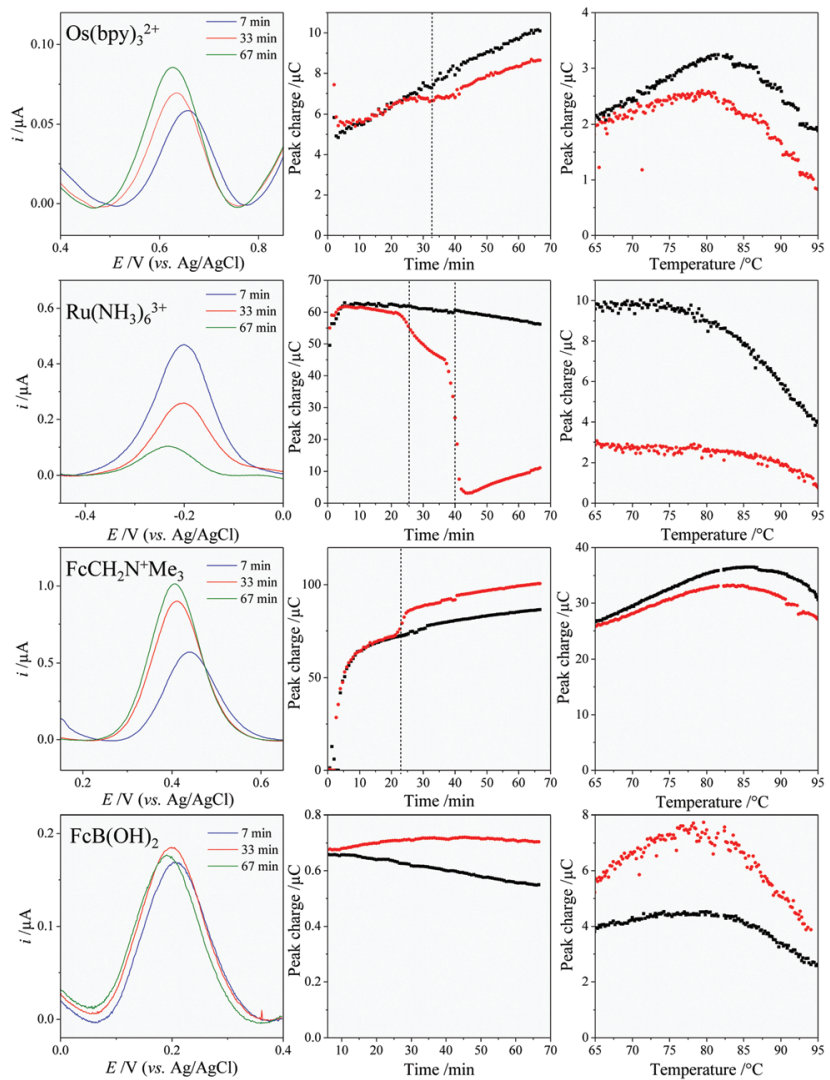

Fig. 2 Non-intercalating redox probe data. The experimental conditions and color codes on the graphs are the same as in Fig. 1. The redox reporters associated with each series of graphs are indicated in the left corner of each SWV graph (from top to bottom): $0.5 \mu \mathrm{M}$ $\mathrm{Os}(\mathrm{bpy})_{3}{ }^{2+}, 15 \mu \mathrm{M} \mathrm{Ru}\left(\mathrm{NH}_{3}\right)_{6}{ }^{3+}, 15 \mu \mathrm{M} \mathrm{FcCH} \mathrm{N}^{+} \mathrm{Me}_{3}$ and $15 \mu \mathrm{M} \mathrm{FcB}(\mathrm{OH})_{2}$.

to plot the characteristic time-course LAMP amplification curves for both positive samples (red curves) and negative template controls (no DNA, black curves).

\section{Intercalating probes}

In Fig. 1, whatever intercalating redox probe was used, a typical exponential signal decrease from a characteristic timeto-threshold value $\left(t_{\mathrm{t}}\right.$, marked on the graph by a vertical dotted line) is observed for the entire positive samples (red curves), but not for the negative controls (black curves). This points to a sudden rise in the concentration of ds-DNA amplicons, which then leads to an abrupt decrease in the free redox-active probe concentration at the expense of the intercalated one. However, comparison of the different probes shows several marked differences not only in the shape of LAMP amplification curves, but also in the time-to-threshold values and signal decrease amplitudes. These differences well illustrate how the choice of a redox probe can significantly affect the analytical response of real-time electrochemical LAMP. Similar to the results previously reported for the electrochemical monitoring of HDA in real-time, ${ }^{13}$ the $\left[\mathrm{Os}(\mathrm{bpy})_{2} \mathrm{dppz}\right]^{2+}$ complex displays a notable positive drift of the SWV response with time. (See the negative control plot which is 3 -fold augmented after $40 \mathrm{~min}$ at $65{ }^{\circ} \mathrm{C}$ before reaching a limiting value.) This large signal increase can be attributed to a favorable partitioning of the osmium complex on the surface of the working carbon electrode, ${ }^{13}$ a phenomenon that depends on probe concentration (Fig. S1†) and that proceeds here at a peculiarly slow rate. Similar baseline drifts are also observed with the two other osmium complexes, but with a slightly lower gain and without showing a saturating value within the time window explored. The behavior of the osmium complexes contrasts with the much more stable baseline responses achieved with $\mathrm{MB}$ and PhP and, to a somewhat lower extent, PyA. These higher signal stabilities indicate a less significant adsorption contribution of the redox probe to the SWV signal. It is nevertheless worthwhile to note that, at the beginning of the SWV measurements, the response of $\mathrm{MB}, \mathrm{PhP}$ or PyA either rapidly or slightly increases or decreases before stabilizing after a few consecutive scans. Such a behavior, suggests again some electrode adsorption effects on the SWV response. These effects however more rapidly relax and stabilize with these aromatic compounds than the osmium complexes. In contrast to its congeners, Nile blue shows such a strong signal decrease with time that at the end of the amplification the negative control signal is only $10 \%$ of its initial value. To understand the origin of this behavior, the UV-visible spectra of Nile blue solutions $(5 \mu \mathrm{M})$ were recorded at $65{ }^{\circ} \mathrm{C}$ as a function of time, in either the presence or absence of the LAMP constituents. The UV-visible spectra slowly but significantly changed in the presence of the LAMP constituents, but not in their absence (Fig. S2 $\dagger$ ). This comportment suggests a slow nonspecific binding of the Nile blue with one of the reagents in the LAMP mix. Independent tests of each of the LAMP constituents allowed us to establish that the PVP surfactant was responsible for the absorbance change (Fig. S2 $\dagger$ ). We therefore concluded that the slow continuous signal decrease of Nile blue with time was the consequence of a nonspecific binding of Nile blue to the PVP surfactant (which, because of the $40 \mathrm{kDa}$ molecular weight of PVP, leads to an apparent mass transport decrease of Nile blue to the sensing electrode surface). This result clearly underlines the importance of optimizing the adjuvants added to the LAMP mix to avoid nonspecific electrochemical response decreases with some redox probes.

Another important inference from the amplification curves of the positive samples in Fig. 1 involves the dependence of the onset-signal and signal amplitude decreases on the nature of the intercalating redox probe. For instance, the $\left[\mathrm{Os}(\mathrm{bpy})_{2} \text { phen }\right]^{2+}$ shows a poor signal amplitude decrease at amplification times greater than $35 \mathrm{~min}$, while under similar conditions the $\left[\mathrm{Os}(\mathrm{bpy})_{2} \mathrm{dppz}\right]^{2+}$ shows a complete signal extinction after only $15 \mathrm{~min}$. The total disappearance of the SWV signal demonstrates that all of the $\left[\mathrm{Os}(\mathrm{bpy})_{2} \mathrm{dppz}\right]^{2+}$ molecules in solution are captured by a relatively small amount of the exponentially grown amplicon. Such contrasting behavior is clearly the consequence of a marked difference in the binding strengths of the osmium complexes for ds-DNA. The stronger the binding affinity of the redox probe to ds-DNA is, the sooner the onset-signal decrease occurs and the larger the 
signal amplitude reduction. This conclusion is supported by the decrease in $t_{\mathrm{t}}$ that occurs as binding strength of the intercalating redox species is increased (see Table 1).

The other critical parameter that governs the sensitivity of the onset-signal decrease is inhibition of the LAMP reaction by the intercalating probe, an effect that generally correlates in PCR with the binding strength of the probe to ds-DNA. ${ }^{38}$ To characterize this inhibitory effect with the stronger intercalating probes (i.e., $\left[\mathrm{Os}(\mathrm{bpy})_{2} \mathrm{dppz}\right]^{2+}, \mathrm{MB}$, and $\mathrm{PhP}$ ), we carried out a series of real-time electrochemical LAMP experiments where the starting concentration of the M13mp18 DNA target was held constant while the redox probe concentration was varied. The $t_{\mathrm{t}}$ value was used as an indicator of the inhibitory effect on LAMP efficiency. Fig. 3 shows the plots of $t_{\mathrm{t}}$ as a function of redox reporter concentration in the LAMP mixtures. Linear relationships were obtained wherein slopes indicate the degree of LAMP inhibition. The latter were clearly related to the binding strength of the intercalating species, showing a steeper slope for the stronger intercalator. The LAMP inhibition produced by the redox probe has therefore a negative impact on the assay sensitivity and assay time. It may thus explain why in spite of having the strongest ds-DNA affinity, $\left[\mathrm{Os}(\mathrm{bpy})_{2} \mathrm{dppz}\right]^{2+}$ does not generate a significantly shorter $t_{\mathrm{t}}$ value compared to $\mathrm{PhP}$ and MB (Table 1). The same reasoning should also apply to the comparison of PhP with MB.

Table 1 Parameters inferred from the electrochemical LAMPs performed with the intercalating redox probes

\begin{tabular}{lcccc}
\hline Compound & $C(\mu \mathrm{M})$ & $K_{\mathrm{b}}{ }^{a}\left(\mathrm{M}^{-1}\right)$ & $t_{\mathrm{t}}{ }^{b}(\mathrm{~min})$ & $T_{\mathrm{m}}{ }^{c}\left({ }^{\circ} \mathrm{C}\right)$ \\
\hline$\left[\mathrm{Os}(\mathrm{bpy})_{2} \mathrm{dppz}\right]^{2+}$ & 0.5 & $5 \times 10^{620}$ & $15.4 \pm 0.8$ & $87.0 \pm 0.3$ \\
$\mathrm{PhP}$ & 15 & $\sim 5 \times 10^{535}$ & $16.4 \pm 0.5$ & $86.5 \pm 0.5$ \\
$\mathrm{MB}$ & 15 & $\sim 5 \times 10^{432-34}$ & $16.8 \pm 2.0$ & $84.9 \pm 0.1$ \\
PyA & 5 & $3 \times 10^{539}$ & $23.2 \pm 6.4$ & $86.4 \pm 0.1$ \\
Nile blue & 5 & $3 \times 10^{437}$ & $22.8 \pm 3.9$ & $85.8 \pm 0.7$ \\
${\left.\text { [Os(bpy }{ }_{2} \text { phen }\right]^{2+}}^{2+}$ & 0.5 & $8 \times 10^{331}$ & $30.8 \pm 6.4$ & $85.8 \pm 0.1$
\end{tabular}

${ }^{a}$ Determined at $25{ }^{\circ} \mathrm{C}$ and for an ionic strength of $\sim 0.05 \mathrm{M}$. ${ }^{b}$ Average time-to-threshold values recovered from 2 to 5 experiments of real-time electrochemical LAMP of $10^{6}$ copies M13mp18 target. ${ }^{c}$ Average value inferred from duplicate or triplicate melting curve experiments.

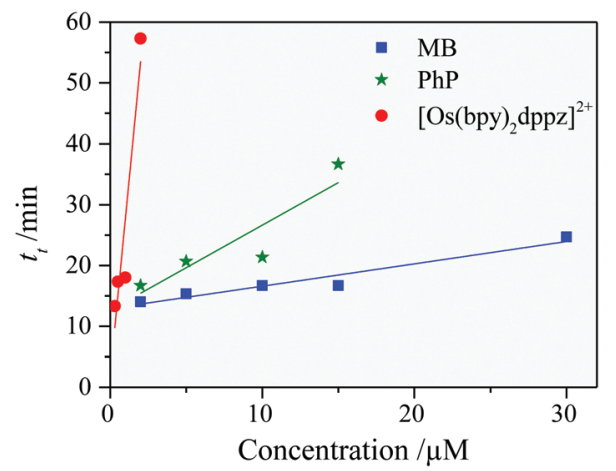

Fig. 3 Comparison of the inhibitory effects of $\left[\mathrm{Os}(\mathrm{bpy})_{2} \mathrm{dppz}\right]^{2+}, \mathrm{PhP}$ and $\mathrm{MB}$ on the $t_{\mathrm{t}}$ values determined from the real-time electrochemical LAMP of $10^{6}$ copies M13mp18 DNA target.
The electrochemical melting curves recorded immediately after the LAMP reaction (last column of graphs in Fig. 1 and 2) also correlate to some extent with the binding strengths of the redox probes. A characteristic sharp increase of the SWV response within a narrow temperature range was observed for the positive samples of all of the intercalating redox reporters. This transition is characteristic of the melting temperature $\left(T_{\mathrm{m}}\right)$ at which the double-stranded DNA amplicons form single-stranded DNA (i.e., the temperature at which half of the DNA duplex is denatured), thereby suddenly increasing the SWV response according to the release of the intercalated redox probe in solution. The signal amplitude and, to a lesser extent, the $T_{\mathrm{m}}$ at which these transitions occur are dependent on the nature of the redox probe. The largest signal amplitude increases are observed for the intercalators having the strongest ds-DNA affinity binding, i.e., $\left[\mathrm{Os}(\mathrm{bpy})_{2} \mathrm{dppz}\right]^{2+}$ and $\mathrm{PhP}$, while the smallest amplitude is recorded for $\left[\mathrm{Os}(\mathrm{bpy})_{2} \mathrm{phen}\right]^{2+}$. The melting transitions of the two strongest intercalators are also localized at slightly higher $T_{\mathrm{m}}$ values compared to the others probes (Table 1), which points to increasing stabilization of the double-stranded amplicons by stronger intercalating species. ${ }^{38} \S$

The well-defined melting transitions observed for all of the intercalating redox probes were unexpected because LAMP typically generates amplicons of different lengths (by the production of a series of concatemers of the target). One would thus expect to see successive transitions in melting curves, characteristic of the different amplicon lengths. This is clearly not the case in our experiments. One explanation for the welldefined single transitions is that when the shorter-length dsDNA amplicons are melted at a low temperature, the released redox probes are rapidly redistributed along the unsaturated non-opened longer amplicons until the most abundant and lengthiest amplicon eventually melts at a higher temperature. This reasoning is consistent with what has been reported for fluorescent dyes. ${ }^{40,41}$

\section{Non-intercalating probes}

In Fig. 2, for the non-intercalating neutral redox probe $\mathrm{FcB}(\mathrm{OH})_{2}$, as expected, no significant change in the LAMP amplification curve was observed. In the case of the non-intercalating positively charged redox reporters, systematic signal transition decreases $\left(\mathrm{Os}(\mathrm{bpy})_{3}{ }^{2+}, \mathrm{Ru}\left(\mathrm{NH}_{3}\right)_{6}{ }^{3+}\right.$ ) or even a signal increase $\left(\mathrm{FcCH}_{2} \mathrm{~N}^{+} \mathrm{Me}_{3}\right)$ were recorded. Most are of very small amplitude except for $\mathrm{Ru}\left(\mathrm{NH}_{3}\right)_{6}{ }^{3+}$ which shows a dramatic change in the kinetic plot of the positive sample, showing a reproducible two-step exponential signal decrease, including an initial low amplitude signal diminution after $26 \mathrm{~min}$ followed by a second much steeper and larger amplitude response decrease at 40 min reaction time (Fig. 2). This behavior suggests a

$\S$ This statement must be qualified by the fact that the melting experiments where not all performed at a same redox probe concentration and that it is wellknown that $T_{\mathrm{m}}$ is significantly influenced by the intercalating probe concentration when the latter is far from saturation of the ds-DNA binding sites. 
two-stage drop in the free concentration of $\mathrm{Ru}\left(\mathrm{NH}_{3}\right)_{6}{ }^{3+}$ during the LAMP reaction, a phenomenon that cannot be attributed to a strong interaction of $\mathrm{Ru}\left(\mathrm{NH}_{3}\right)_{6}{ }^{3+}$ with ds-DNA because of the absence of a signal transition in the melting curve analysis (clearly confirming no ds-DNA intercalation by $\mathrm{Ru}\left(\mathrm{NH}_{3}\right)_{6}{ }^{3+}$ ). The onset-exponential decrease also occurs at a much longer LAMP amplification time than with the strong intercalating redox reporters, a result that demonstrates that a lower LAMP sensitivity is associated with this particular probe. Regardless of this lack of sensitivity, $\mathrm{Ru}\left(\mathrm{NH}_{3}\right)_{6}{ }^{3+}$ remains a valuable reporter in real-time electrochemical LAMP because it gives a low electrochemical response decrease in the absence of target and a large signal amplitude drop with positive samples (the SWV current decrease nearly down to zero). This is advantageous for more easily and reliably extracting the time-tothreshold values from the amplification curves of positive samples.

The two-step signal decrease observed with $\mathrm{Ru}\left(\mathrm{NH}_{3}\right)_{6}{ }^{3+}$ suggests the involvement of different types of non-intercalating interactions between the cationic redox probe and the DNA products and/or byproducts generated during LAMP (either by electrostatic binding of $\mathrm{Ru}\left(\mathrm{NH}_{3}\right)_{6}{ }^{3+}$ to the anionic DNA backbone ${ }^{42}$ or through ion-pairing reaction between $\mathrm{Ru}\left(\mathrm{NH}_{3}\right)_{6}{ }^{3+}$ and the pyrophosphate anions generated by LAMP). These non-intercalating interactions have been revealed by real-time monitoring of the $\mathrm{SWV}$ response of $\mathrm{Ru}\left(\mathrm{NH}_{3}\right)_{6}{ }^{3+}$ under LAMP conditions during stepwise addition of pyrophosphate anion to the solution (Fig. S3†). The abrupt decrease of the SWV peak charge observed when the pyrophosphate concentration is raised to a critical value beyond $1 \mathrm{mM}$ strongly supports the formation of a co-precipitate between the pyrophosphate anions and $\mathrm{Ru}\left(\mathrm{NH}_{3}\right)_{6}{ }^{3+}$. This conclusion is corroborated by the fact that $\sim 1 \mathrm{mM}$ pyrophosphate is within the range of concentrations that is normally released at the end of a LAMP reaction. We thus propose that the second large and abrupt signal decrease in the LAMP amplification curve results from the co-precipitation of $\mathrm{Ru}\left(\mathrm{NH}_{3}\right)_{6}{ }^{3+}$ with the millimolar concentrations of pyrophosphate anion generated enzymatically, while the first low amplitude signal decrease is related to weak nonspecific electrostatic interactions between $\mathrm{Ru}\left(\mathrm{NH}_{3}\right)_{6}{ }^{3+}$ and DNA amplicons. It is worth noting that such electrostatic interactions are reminiscent of cationic probes because even in the case of intercalating redox dyes such as $\mathrm{MB}$ and $\mathrm{PhP}$, a systematic second signal decrease of very small amplitude is observed in the amplification curves of positive samples (as specified by the dashed arrow on the graphs of MB and PhP in Fig. 1). Certainly, the most unexpected result is the small signal increase that was reproducibly obtained with $\mathrm{FcCH}_{2} \mathrm{~N}^{+} \mathrm{Me}_{3}$ in the amplification curves of positive samples. While we have for the moment no explanation to account for this surprising result, it is possible that electrode accessibility to the cationic redox compound becomes slightly more favorable when the amplicon concentration is raised up to a certain value. Further studies are required to better understand the underlying reasons for this unexpected behavior.

\section{Conclusions}

Following our screening of different redox probes, we can conclude that there are a number of intercalating and non-intercalating compounds suitable for electrochemically monitoring LAMP in real-time. Among the 10 redox reporters tested, the most attractive are those able to intercalate into ds-DNA, as they provide higher LAMP sensitivity (or faster LAMP assay) and a greater signal amplitude compared to non-intercalating molecules. The intercalating probes also offer the possibility of determining DNA melting temperature at the end of the LAMP reaction, and thus possess a decisive advantage over non-intercalating probes for identifying and discriminating true from false amplification reactions. Our comparative study also shows that the most favorable probes for electrochemical LAMP are those having a binding strength that is high enough to allow association with ds-DNA target (improved sensitivity), while still being low enough to avoid inhibiting the LAMP reaction (decreased sensitivity). There are also some redox probes leading to significant positive or negative baseline drifts, a behavior that can affect a reliable $t_{\mathrm{t}}$ recovery from positive amplification curves. This is particularly true if baseline drifts are not a linear function of time and not sufficiently reproducible from one sample to another. It is also important to optimize the adjuvants added to the LAMP mix, as some of them can interact with the free-to-diffuse redox probe and thus can lead to a nonspecific electrochemical response decrease with time.

Among the various redox-active probes we have tested, the best results were obtained with the strongest ds-DNA intercalators: $\left[\mathrm{Os}(\mathrm{bpy})_{2} \mathrm{dppz}\right]^{2+}, \mathrm{MB}$, and PhP. While they featured the earliest and largest signal decreases, not all were equivalent. For instance, though $\left[\mathrm{Os}(\mathrm{bpy})_{2} \mathrm{dppz}\right]^{2+}$ was found to be very effective for monitoring LAMP, it had a baseline drift that made signal threshold recovery difficult. It also significantly inhibited the LAMP reaction at micromolar concentrations (as previously shown in $\mathrm{PCR}$ or $\mathrm{HDA}^{13,20}$ ), requiring one to perform LAMP in the presence of barely detectable, submicromolar probe concentrations. In comparison, the $\mathrm{MB}$ and $\mathrm{PhP}$ probes did not suffer from this drawback, making them far more suitable and attractive for use in real-time electrochemical LAMP.

The non-intercalating compound $\mathrm{Ru}\left(\mathrm{NH}_{3}\right)_{6}{ }^{3+}$ has also been confirmed as a valuable redox reporter, but contrary to what has been previously published, ${ }^{22}$ it is not through a direct electrostatic interaction with ds-DNA that the principal signal decrease component occurs, but through an ion-pairing interaction with the pyrophosphate anion generated by LAMP. It has however the disadvantage of delivering a retarded onset signal decrease compared to the intercalating redox reporters, giving rise to significantly lower LAMP sensitivity.

The present analysis of 10 redox reporters has finally allowed us to establish guidelines for optimizing real-time electrochemical LAMPs. These guidelines are expected to greatly facilitate the design and optimization of new and improved redox probes for LAMP, and to promote the widespread adoption of this technique toward DNA testing 
applications. It is also anticipated to stimulate the development of new real-time electrochemical monitoring of isothermal DNA amplifications.

\section{Acknowledgements}

This work was supported by the Ile-de-France region via the DIM Analytics. A. Martin thanks the DIM Analytics for its Ph. D. fellowship.

\section{Notes and references}

1 S. Park, Y. Zhang, S. Lin, T.-H. Wang and S. Yang, Biotechnol. Adv., 2011, 29, 830-839.

2 A. Niemz, T. M. Ferguson and D. S. Boyle, Trends Biotechnol., 2011, 29, 240-250.

3 M. G. Roper, C. J. Easley and J. P. Landers, Anal. Chem., 2005, 77, 3887-3893.

4 Y. Zhang and P. Ozdemir, Microfluidic DNA amplification A review, Anal. Chim. Acta, 2009, 638, 115-125.

5 L. Chen, A. Manz and P. J. R. Day, Lab Chip, 2007, 7, 14131423.

6 T. M. Lee and I. M. Hsing, Anal. Chim. Acta, 2006, 556, 2637.

7 A. S. Patterson, K. Hsieh, H. T. Soh and K. W. Plaxco, Trends Biotechnol., 2013, 31, 704-712.

8 X. Zhang, S. B. Lowe and J. J. Gooding, Biosens. Bioelectron., 2014, 61, 491-499.

9 T. Goda, M. Tabata and Y. Miyahara, Front. Bioeng. Biotechnol., 2015, 3, 1-15.

10 P. J. Asiello and A. J. Baeumner, Lab Chip, 2011, 11, 14201430.

11 P. Craw and W. Balachandran, Lab Chip, 2012, 12, 24692486.

12 K. Hsieh, B. S. Ferguson, M. Eisenstein, K. W. Plaxco and H. T. Soh, Acc. Chem. Res., 2015, 911-920.

13 F. Kivlehan, F. Mavre, L. Talini, B. Limoges and D. Marchal, Analyst, 2011, 136, 3635-3642.

14 N. Nagatani, K. Yamanaka, M. Saito, R. Koketsu, T. Sasaki, K. Ikuta, T. Miyahara and E. Tamiya, Analyst, 2011, 136, 5143-5150.

15 K. Hsieh, A. S. Patterson, B. S. Ferguson, K. W. Plaxco and H. T. Soh, Angew. Chem., Int. Ed., 2012, 51, 4896-4900.

16 D. Jiang, G. Xiang, J. Wu, C. Liu, F. Liu and X. Pu, Int. J. Electrochem. Sci., 2012, 7, 5273-5285.

17 G. Xiang, X. Pu, D. Jiang, L. Liu, C. Liu and X. Liu, PLoS One, 2013, 8, e72342.

18 E. Salm, Y. Zhong, B. Reddy Jr., C. Duarte-Guevara, V. Swaminathan, Y. S. Liu and R. Bashir, Anal. Chem., 2014, 86, 6968-6975.

19 J. Luo, X. Fang, D. Ye, H. Li, H. Chen, S. Zhang and J. Kong, Biosens. Bioelectron., 2014, 60, 84-91.
20 T. Deféver, M. Druet, D. Evrard, D. Marchal and B. Limoges, Anal. Chem., 2011, 83, 1815-1821.

21 B. Limoges, T. Deféver and D. Marchal, WO2009147322 A1, 2009.

22 M. U. Ahmed, S. Nahar, M. Safavieh and M. Zourob, Analyst, 2013, 138, 907-915.

23 T. Notomi, H. Okayama, H. Masubuchi, T. Yonekawa, K. Watanabe, N. Amino and T. Hase, Nucleic Acids Res., 2000, 28, e63.

24 R. Miranda-Castro, D. Marchal, B. Limoges and F. Mavré, Chem. Commun., 2012, 48, 8772-8774.

25 K. Maruyama, Y. Mishima, K. Minagawa and J. Motonaka, J. Electroanal. Chem., 2001, 510, 96-102.

26 B. Wilson, M.-J. Fernández, A. Lorente and K. B. Grant, Org. Biomol. Chem., 2008, 6, 4026-4035.

27 L. Bouffier, B. Baldeyrou, M.-P. Hildebrand, A. Lansiaux, M.-H. David-Cordonnier, D. Carrez, A. Croisy, O. Renaudet, P. Dumy and M. Demeunynck, Bioorg. Med. Chem., 2006, 14, 7520-7530.

28 L. Bouffier, I. Gosse, M. Demeunynck and P. Mailley, Bioelectrochemistry, 2012, 88, 103-109.

29 K. Maruyama, Y. Mishima, K. Minagawa and J. Motonaka, Anal. Chem., 2002, 74, 3698-3703.

30 A. E. Friedman, J. C. Chambron, J. P. Sauvage, N. J. Turro and J. K. Barton, J. Am. Chem. Soc., 1990, 112, 4960-4962.

31 F. Pierard, A. Del Guerzo, A. K. Mesmaeker, M. Demeunynck and J. Lhomme, Phys. Chem. Chem. Phys., 2001, 3, 2911-2920.

32 L. Z. Zhang and G.-Q. Tang, J. Photochem. Photobiol., B, 2004, 74, 119-125.

33 S. F. Baranovskii, P. A. Bolotin, M. P. Evstigneev and D. N. Chernyshev, J. Appl. Spectrosc., 2008, 75, 251259.

34 S. Nafisi, A. A. Saboury, N. Keramat, J.-F. Neault and H.-A. Tajmir-Riahi, J. Mol. Struct., 2007, 827, 35-43.

35 B. Wilson, M.-J. Fernández, A. Lorente and K. B. Grant, Tetrahedron, 2008, 64, 3429-3436.

36 K. M. Marshall and L. R. Barrows, Nat. Prod. Rep., 2004, 21, 731-751.

37 H. Ju, Y. Ye and Y. Zhu, Electrochim. Acta, 2005, 50, 13611367.

38 H. Gudnason, M. Dufva, D. D. Bang and A. Wolff, Nucleic Acids Res., 2007, 35, e127.

39 B. Wang, L. Bouffier, M. Demeunynck, P. Mailley, A. Roget, T. Livache and P. Dumy, Bioelectrochemistry, 2004, 63, 233237.

40 G. J. Randhawa, M. Singh, D. Morisset, P. Sood and J. Zel, J. Agric. Food Chem., 2013, 61, 11338-11346.

41 C. Liu, E. Geva, M. Mauk, X. Qiu, W. R. Abrams, D. Malamud, K. Curits, S. M. Owen and H. H. Bau, Analyst, 2011, 136, 2069-2076.

42 A. B. Steel, T. M. Herne and M. J. Tarlov, Bioconjugate Chem., 1999, 10, 419-423. 